\section{Malignant Pleural Effusion}

The treatment of pleural effusion is a common problem in the management of patients with malignant disease. A large effusion will produce severe dyspnoea and eventually death from respiratory failure; repeated paracentesis may be followed by manifestations of protein depletion; and troublesome cough and pain in the chest often add to the patient's discomfort. The primary tumour occurs most commonly in the bronchus in the male and breast in the female, but it may arise in any organ. The cause of the effusion is exudation from the tumour cells or obstruction of venous or lymphatic drainage, or both. In bronchial lesions a non-malignant effusion may occur secondary to pulmonary infection.

In some cases drug therapy may greatly reduce or even arrest the production of pleural fluid, as occurs, for example, in the use of oral chlorambucil in advanced ovarian carcinoma. ${ }^{1}$ In others, however, the choice of therapy normally lies between conservative management with repeated aspiration and an attempt at pleurodesis. The decision will depend upon the patient's general condition, the probable duration of survival, and the rate of reaccumulation of liquid after aspiration. In patients who are moribund, occasional thoracentesis to relieve dyspnoea, oral prednisone, ${ }^{2}$ and sedation are usually the wisest method of management. Nevertheless, patients whose general condition is good may survive for relatively long periods-two years or more-after the development of malignant effusion, especially those suffering from cancer of the breast, and in them pleurodesis may produce appreciable improvement.

A variety of agents have been used to obtain pleurodesis. Good results have been obtained by large-tube intercostal drainage supplemented by suction. ${ }^{3}$ Alkylating agents such as nitrogen mustard or thiotepa and radioisotopes such as gold-198 or yttrium- $90^{4}$ are successful in about half the cases. The former, however, may produce serious sideeffects, while the latter are not always readily available. Stripping of the parietal pleura at thoracotomy has also been used, ${ }^{5}$ but this method may upset the patient unduly and most people think that it is unnecessarily radical.

Intrapleural talc is known to be highly effective for obtaining pleurodesis, both in spontaneous pneumothorax ${ }^{6}$ and in malignant effusions, ${ }^{7}$ and several techniques have been

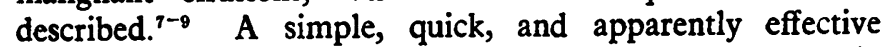
method of inducing pleurodesis by the introduction of talc in the form of an aerosol has recently been described by $\mathbf{R}$. $\mathbf{H}$. Adler and B. W. Rappole. ${ }^{10}$ The aerosol unit is manufactured from metal which is sterilized by irradiation and light enough to be held easily in one hand. An intercostal catheter is inserted through a cannula and all the fluid is aspirated from the pleural space. The small catheter of the aerosol unit is then inserted through the cannula until its tip just projects into the pleural space. The tip of the catheter is rotated in several directions as the aerosol is sprayed in.

' Zelenik, J. S., Halpern, A. J., and Williams, D. W., Obstet. and Gynec., 1964, 23, 707.

2 Leckie, W. J. H., and Tothill, P., Clin. Sci., 1965, 29, 339.

- Lambert, C. J., Shah, H. H., Urschel, H. C., jun., and Paulson, D. L., Ann. thorac., Surg., 1967, 3, 1.

- Ann. thorac. Surg., 1967, 3, 761.

- MacKay, N., Lancet, 1957, 2, 761.

: Jensik, R., et al., f. thorac. cardiovasc. Surg., 1963, 46, 322.

' Smith, W. G., and Rothwell, P. P. G., Thorax, 1962, 17, 34

- Bethune, N., F. thorac. Surg., 1935, 4, 251.

- Pearson, F.'G., and MacGregor, D. C., F. thorac. cardiovasc. Surg., 1966, 51, 732 .

10 Adler, R. H., and Rappole, B. W., Surgery, 1967, 62, 1000.
The entire procedure takes less than half a minute, and a large drainage tube is then left in situ for $\mathbf{4 8}$ to $\mathbf{7 2}$ hours to ensure that the pleural space is maintained free from fluidan important factor in any method of pleurodesis in malignant effusions. This simple technique merits further trial.

\section{Thoughts on Education}

Whatever may be the fate of the Royal Commission's report on medical education, ${ }^{1}$ many of the ideas it advances will inevitably be put into practice, for they clarify and add fresh vigour to proposals already in the air or the subject of experiment. "It is no doubt its accurate reflection of existing trends which has resulted in the Commission's Report receiving a generally favourable reception." These words from an editorial in the latest issue of the British fournal of Medical Education $^{2}$ nevertheless preface a series of articles in which expert contributors have criticisms to make of the report from their special points of view.

Pungent criticism of the gulf separating the London teaching hospitals from London University comes from Professor C. R. B. Blackburn, of the University of Sydney, who believes that "If the London system can be abolished the Todd Committee will deserve the praise properly due to it for its Report." Professor J. N. Morris, of the London School of Hygiene and Tropical Medicine, thinks the Commission made too little use of existing data to forecast future needs and has some suggestions of his own. Meeting the cost of the Commission's recommendations, a matter on which the Government has so far expressed no view, evokes the proposal from Professor K. R. Hill, of the Royal Free Hospital, that "realistic fees" of about $£ 1,000$ per annum must be charged to students by the medical schools. The realism is admittedly something of a fiction, for the actual cost is said to be nearer $£ 3,000$ per annum and the majority of students are subsidized by the State anyway, but Professor Hill considers that advantages could come by public finance through more than one channel. Other contributors discuss the report's recommendations on general practice, the selection of students, administration, and research.

It may be true that "In most instances the actual substance taught and learned in medical schools changes more slowly than does the language used to announce the novelty of the curriculum." But medical education is in a healthy phase of evolution. It deserves to be the subject of study, argument, and experiment if it is to reflect the ever-changing course of medicine itself. The latest contribution from the British fournal of Medical Education is therefore timely.

We record with great regret the death on $23 \mathrm{July}$ of Sir Henry Dale, O.M., F.R.S., at the age of 93.

\footnotetext{
Royal Commission on Medical Education, 1965-68: Repori, 1968 Cmnd. 3569. H.M.S.O.

2 British Fournal of Medical Education, 1968, 2, No. 2. British Medical Association, London.

"Stetten, De W., Science, 1968, 160, 1293.
} 